\title{
International Registration of Cultivar Names for Unassigned Woody Genera 1991
}

\author{
Donald G. Huttleston ${ }^{1}$ \\ Longwood Gardens, Box 501, Kennett Square, PA 19348-0501, USA
}

During 1991, seven cultivar names in unassigned woody genera were registered. Anyone who is involved in the origination or introduction of new cultivars of ornamental plants is urged to assure that the names are registered with a view toward nomenclatural stabilization. A list of the International Registration Authorities is available from the American Association of Botanical Gardens and Arboreta (AABGA), 786 Church Road, Wayne, PA 19087, USA.

Acer xfreemanii E. Murray 'Jeffersred'. Registered 16 Feb. 1991. Registrant: Bruce A. Jeffers, 3125 Schneider Road, Toledo, OH 43614, USA. The original plant was first observed in Fostoria, Ohio, by the late Glenn A. Jeffers, father of the registrant, because of its upright habit with good crotch angles, its rapid growth, its exceptional scarlet fall color, and its broad, ovate form. The 28-year-old tree was $13.5 \mathrm{~m}$ tall with a spread of $9 \mathrm{~m}$. It grows $45 \mathrm{~cm}$ a year. The cultivar is described on page 28 of Willet N. Wandell's "Handbook of Landscape Tree Cultivars" under the name "Autumn Blaze." That name was trademarked (\#4867) in July 1982 rendering its use as a cultivar name illegal.

Euonymus fortunei (Turcz.) Hand.-Mazz. 'Surespot'. Registered 21 Aug. 1991. Registrant: Martinus Koole, 1776 4th Avenue, St. Catherine, Ont. L2R 6P9, Canada. This cultivar was selected as a sport in Brucedale Gardens in St. Catherine, Ont., by Koole in 1982 because of its compact habit and its slightly curled, dark-green leaves with brightyellow centers. A 7-year-old plant was $30 \mathrm{~cm}$ high with a spread of 3.5 $\mathrm{m}$. It is hardy in Canada Dept. of Agriculture Zone 5. It was commercially introduced in 1989.

Hibiscus syriacus L. 'Winifred Stepney'. Registered 6 Dec. 1991. Registrant: R.P. Baker, 8 Grove Footpath, Surbiton, Surrey KT5 8AT, England, U.K. The original plant of this selection was growing in Kingston-upon-Thames. It was chosen in 1986 by Baker because of its distinctive growth habit and its soft deep rose (RHS 70B), dark centered $15-\mathrm{cm}$ flowers. It has one trunk that produces several upright branches beginning near the ground, forming a neat, compact head. A 4-year-old plant was $73 \mathrm{~cm}$ tall with a spread of only $25 \mathrm{~cm}$. It is hardy in USDA Zone 5.
Leucothoe axillaris (Lam.) D. Don. 'Greensprite'. Registered 28 June 1991. Registrant: Dr. Richard W. Lighty, Mt. Cuba Center, P.O. Box 3570, Greenville, DE 19807, USA. Lighty selected a plant cultivated at Mt. Cuba Center in 1984 because of its graceful, arching habit and its glossy evergreen, slightly twisted leaves. A 20 -year-old plant is 1.5 to 2 $\mathrm{m}$ tall with a $3 \mathrm{~m}$ spread. It is sun tolerant but looks best in shade. It is hardy in USDA Zone 6.

Leucothoe axillaris (Lam.) D. Don. 'Redsprite'. Registered 28 June 1991. Registrant: Dr. Richard W. Lighty, Mt. Cuba Center, P.O. Box 3570, Greenville, DE 19807, USA. Lighty selected a plant cultivated at Mt. Cuba Center in 1984 because of its uniform purple-red winter coloration and its bright red spring shoots. A 15-year-old plant is $2 \mathrm{~m}$ tall with a $2.5 \mathrm{~m}$ spread. It does well in sun or shade provided it has moisture. It is hardy to USDA Zone 6.

Nothofagus antarctica (Forst.) Oerst. 'Puget Pillar'. Registered 23 Dec. 1991. Registrant: Timothy C. Hohn, Washington Park Arboretum XD-10, Univ. of Washington, Seattle, WA 98195, USA. The staff selected a tree in the Arboretum in 1975 because of its neat conical to ovate form in contrast to the open-headed shape typical of the species. For the first 20 years, it is conical to pyramidal with a prominent leader. Later it becomes ovate with a less prominent leader. A 40-year-old tree is $14 \mathrm{~m}$ tall with a $4 \mathrm{~m}$ spread. It is adaptable but not recommended for calcareous soil and is hardy in USDA Zone 7. It does best in cool, moist, or warm, dry summers. A cultivar description was published in the Feb. 1991 issue of American Nurseryman.

Penstemon fruticosus (Pursh) Greene 'Purple Haze'. Registered 18 June 1991. Registrant: Dr. Gerald B. Straley, Univ. of British Columbia, 6804 S.W. Marine Dr., Vancouver, B.C. V6T 1Z4, Canada. The original plant, cultivated at the UBC Botanical Garden, was selected by the staff in 1975. It is a low-spreading, semievergreen subshrub that is attractive all seasons but is covered with mauve-purple flowers from April to June in Vancouver. A 5-year-old plant is $20 \mathrm{~cm}$ tall with a $67 \mathrm{~cm}$ spread. It is sun tolerant and needs very good drainage. It was described on page 19 of the Feb. 1991 issue of Landscape Trades magazine.

${ }^{1}$ Horticultural Taxonomist, retired, Longwood Gardens. 